\title{
Power up! A Pilot Study of a Positive Psychology Intervention for Mental Health Professionals in Greece
}

\author{
Eirini Karakasidou, Georgia Raftopoulou, Michael Galanakis, Anastassios Stalikas \\ Panteion University, Athens, Greece \\ Email: irenekarakasidou@yahoo.com
}

How to cite this paper: Karakasidou, E., Raftopoulou, G., Galanakis, M., \& Stalikas, A. (2021). Power up! A Pilot Study of a Positive Psychology Intervention for Mental Health Professionals in Greece. Psychology, 12, 976-991.

https://doi.org/10.4236/psych.2021.126059

Received: May 13, 2021

Accepted: June 27, 2021

Published: June 30, 2021

Copyright ( 2021 by author(s) and Scientific Research Publishing Inc. This work is licensed under the Creative Commons Attribution International License (CC BY 4.0).

http://creativecommons.org/licenses/by/4.0/

\section{(c) (i) Open Access}

\begin{abstract}
This survey aimed to investigate the value of self-compassion for psychologists while also examining differences in Empathy and quality of life before and after the intervention. A total number of 29 psychotherapists active in practice participated in the current studies. The experiment involved two groups: the experimental $(N=9, M=29.89)$ and the control group $(N=20, M=$ 31.05). Results indicated a statistically significant increase in self-compassion for the experimental condition. Life satisfaction was also significantly increased in the experimental group. The difference between the intervention and control groups in the follow-measurement of self-compassion remained statistically significant.
\end{abstract}

\section{Keywords}

Self-Compassion, Positive Psychology Intervention, Mental Health Professionals

\section{Introduction}

According to Neff (2018) and colleagues, various surveys have proved the fundamental role of self-compassion in decreasing various symptoms and increasing well-being. In particular, it seems that increased levels of self-compassion are linked to a variety of positive outcomes in multiple areas of life, such as positive psychological health, sleep quality, positive emotions, emotional intelligence, body image, and close interpersonal relationships, social interaction and balance in the sympathetic nervous system. Compassion towards oneself is a core component for a person to feel secure, connected to the world and calm, particularly in difficult situations (Gilbert, 2005). According to Muris (2016), psychological 
health can be boosted by self-compassion's positive and soothing elements. Seligowski (2015) and his colleagues also showed a statistically significant positive correlation between self-compassion and overall psychological health. When a person acts with self-compassion, they seem to be more balanced in a personal struggle with less extreme attitudes (Neff, Long, Knox, Davidson, Kuchar, Costigan, \& Breines, 2018). Also, it seems to be a core skill in professions that require emotional intelligence for individuals to relate and understand others such as nurses (Şenyuva, Kaya, Işik \& Bodur, 2014).

\subsection{The Value of Self-Compassion for Psychologists}

Although all research efforts contribute significantly to understanding the link between self-compassion and positive psychological effects, very few generalise this relationship in populations with high occupational risk rates. A sector that needs more deliberation about levels of self-compassion and self-care is the psychological sector. The majority of psychologists face many difficulties in their daily practice with clinical populations (Kally, 2017). On the one hand, psychologists share compassion with the people who need it, and this process, in many cases, generates the feeling of satisfaction and fullness (Lown, 2015). Concurrently, continued contact with clients who experience personal difficulties and traumatic experiences can lead to compassion fatigue. Compassion fatigue occurs suddenly and creates tension, nervousness and a sense of helplessness (Ledoux, 2015; Potter, Deshields, Divanbeigi, Berger, Cipriano, Norris \& Olsen, 2010). Other changes observed in psychologists include lack of patience, secondary trauma anxiety and difficulty interacting with people in the social and family environment, lack of Empathy, lack of life satisfaction, selective attention, memory disturbance and low decision making (Killian, 2008; Richardson, Jaber, Chan, Jesse, Kaur, \& Sangha, 2016; Gilroy, Carroll \& Murra, 2002; Finlay-Jones, Rees \& Kane, 2015).

Surveys involving psychologists' practice have shown high levels of emotional and physical exhaustion and burnout associated with variables, such as low rates of work-related assistance and supervision, professional framework public or private, the request of administrative tasks, payment, the number of clients, high caseload demands and lack of self-awareness and self-care (Ackerley, Burnell, Holder \& Kurdek, 1988; Rupert \& Morgan, 2005).

Exploring new interventions and experimenting with new approaches are imperative in protecting this occupation category. Additionally, several surveys demonstrated a strong negative correlation between self-compassion and compassion fatigue (Finlay-Jones, Rees, \& Kane, 2015; Schaafsma, 2018). Even brief interventions can play a fundamental role in teaching the core components of self-compassion (Finlay-Jones, 2014). Clinicians who follow such interventions seem to enhance the therapeutic relationship with their clients. They maintain their wellbeing, and they are protected by situations that may put this therapeutic relationship at risks, such as emotional exhaustion and fatigue, negative affect 
and rumination, even in the long term (Boellinghaus, Jones, \& Hutton, 2014; Kemper et al., 2015; Shapiro, Brown \& Biegel, 2007).

Richardson (2016) and his colleagues illustrated the value of compassion for oneself and others in professional satisfaction in a sample of medical students. Their survey demonstrates that high levels of self-compassion reduce rates of work fatigue and burnout. A randomised control trial of an 8-weeks intervention program, which included Mindfulness, helped mental health professionals reduce stress, increase self-compassion rates, and ameliorate their overall prosperity (Shapiro et al., 2005). Another randomised controlled trial among psychologists shows that self-compassion training can teach participants the distinction between self-compassion and self-coldness, but also can reduce self-coldness (Eriksson, Germundsjö, Åström, \& Rönnlund, 2018). Three systematic literature reviews demonstrated that all forms of interventions based on Mindfulness seem to reduce overall anxiety and promote self-care, wellbeing and Empathy in health care professionals (Boellinghaus et al., 2014; Burton, Burgess, Dean, Koutsopoulou, \& Hugh-Jones, 2017; Raab, 2014). Specifically, female therapists seem to experience significant benefits at the level of thinking, feeling and body through such interventions (Dorian \& Killebrew, 2014).

\subsection{Empathy}

Some research efforts relate self-compassion to Empathy. Empathy is defined as an individual's ability to perceive and take into account the point of view, the feelings, the thoughts, and the experience of another person. Surveys have shown that self-criticism may affect the possibility of generating an empathetic and compassionate relationship with others (Birnie, Speca, \& Carlson, 2010; Kingsbury, 2009). In agreement with these findings, Raab (2014) illustrates that the most crucial component in creating an interpersonal relationship is compassion. But people who tend to be more critical of themselves are expected to be more vital than others. It seems that self-compassion is necessary for a person to take others' opinions into account and be empathetic. Duarte and his colleagues (2016) showed that self-compassion could increase positive emotions and quality in the workplace and protect individuals from compassion fatigue and empathy reduction.

\subsection{Life Satisfaction}

Several studies have shown that self-compassion is a variable that can affect the general psychological state, perceived stress, the severity of distress symptoms, and increase life satisfaction (Neff \& Vonk, 2009; Shapiro, Astin, Bishop, \& Cordova, 2005). Seligowski (2015) and his colleagues have demonstrated the value of compassion in well-being, life satisfaction, and feelings of social connection in individuals who have survived traumatic conditions. Yang (2016) and his colleagues also found a strong positive correlation between self-compassion and perceived hope and life satisfaction. Neff (2008) and colleagues have studied the 
contribution of self-compassion in reducing depression and increasing satisfaction for life in three different cultures (Thailand, US and Taiwan). The results were typical to all three. Many other studies agree on these findings and link self-compassion with strong positive traits, such as gratitude, optimism, happiness and life satisfaction (Albertson, Neff \& Dill-Shackleford, 2015; Neff, 2016; Zessin et al. 2015).

\subsection{Self-Compassion Experimental Methodologies and Interventions}

Self-concentration seems to be associated with mental resilience, resistance to adverse situations and coping with negative life events (Ehret, Joormann, \& Berking, 2015; Kemper, Mo, \& Khayat, 2015). For this reason, in recent years, some researchers have been trying to empirically evaluate the effects of interventions to raise the levels of compassion towards oneself. Neff \& Germer (2013) developed an 8-week group intervention in which individuals participate once a week for approximately 120 minutes. This intervention consists of 8 exercises: Discovering mindful self-compassion, Practicing Mindfulness, Practicing loving-kindness meditation Finding your compassionate voice, Transforming relationships, Living deeply, Managing difficult emotions, Embracing your life aimed at increasing levels of self-compassion (Germer \& Neff, 2013). These exercises seem to reduce symptoms of depression, anxiety and stress, emotional avoidance, and rumination. It is also demonstrated that compassion for oneself, compassion for others, well-being, social connectedness, confidence, and optimism increase significantly after experiencing the 8-week program (Barnard \& Curry, 2011; Smeets, Neff, Alberts, \& Peters, 2014). Recently, Mantelou \& Karakasidou (2017) showed that a brief 3-week self-compassion intervention could also increase positive affect levels, life satisfaction and happiness. Additionally, these interventions have been studied in clinical and non-clinical populations, but also in specific population groups such as athletes, cancer survivors, people diagnosed with eating disorders, adolescence with encouraging results in reducing levels of self-criticism, morbid rumination, and self-criticisms over common human mistakes and insufficiencies (Campo, Bluth, Santacroce, Knapik, Tan Gold, \& Asher, 2017; Donovan, Rodgers, Cousineau, McGowan, Luk, Yates, \& Franko, 2016; Kelly \& Carter, 2015; Mosewich, Crocker, Kowalski, \& DeLongis, 2013).

\subsection{The Current Study}

Considering the evidence provided by international literature, continued contact with clients who experience personal difficulties and traumatic experiences can lead psychologists to compassion fatigue, secondary trauma and secondary anxiety. It may also cause a lack of Empathy, lack of life satisfaction, burnout effects, selective attention, memory disturbance and low decision making (Kally, 2017, Richardson, Jaber, Chan, Jesse, Kaur, \& Sangha, 2016; Ledoux, 2015; Gi- 
lroy, Carroll \& Murra, 2002; Finlay-Jones, Rees, \& Kane, 2015). The emerge of these symptoms affects the patient and the whole therapeutic process primarily. The need to find an effective and immediate intervention to limit the signs of compassion fatigue, burnout and self-judgment are more imperative than ever (Burton et al., 2017).

Unfortunately, there are very poor research data on this generalised health problem. Very few interventions have measured its elimination experimentally. Hence, this research aims to study the value of self-compassion in this group. In particular, the aim was to investigate the possibility of training psychologists in self-compassion while also examining differences in Empathy and quality of life before and after the intervention. In conclusion, the research's main question was the following: Can a brief self-compassion intervention increase self-compassion among psychologists? Specifically, the aim was to investigate the following research hypotheses:

1) Is a 3-weeks self-compassion intervention effective in increasing self-compassion rates, empathy levels and life satisfaction levels on an experimental group of psychologists?

2) Do the increased levels of self-compassion, Empathy, and life satisfaction in the experimental group remain high after a 2-month follow-up?

\section{Method}

\subsection{Participants}

A total number of 29 individuals, psychotherapists active in practice participated in the current studies. Participants were divided into two groups before the intervention's initiation, based on their availability to participate in the intervention organised for this study's aim. The experimental group consisted of 9 participants, and the control group consisted of 20 participants. The intervention lasted three weeks, during which the experimental group was taught three self-compassion exercises. In the control condition, there was no intervention. All participants were given pre and post-tests and a follow-up test after two months. The independent variable was the intervention of increasing self-compassion. The dependent variables were self-compassion, Empathy and quality of life.

In the experimental group $(N=9)$, two of the participants were men $(22.2 \%)$, and 21 of the participants were women (77.8\%), with an age range of $25-37$ years old $(M=29.89, S D=4.16)$. Concerning their educational level, $44.4 \%$ hold a Bachelor's Degree and 55.6\% have a Master's degree. As far as it concerns their marital status, $66.7 \%$ are single, and $33.3 \%$ are married. The therapeutic approaches identified in the experimental group are Cognitive Therapy (29.6\%), Behavioral Therapy (33.3\%), Psychodynamic (11.1\%), Art Therapy (11.1\%) and Other (14.8\%), with clinical experience in Private Practice (66.7\%), Public sector (11.1\%) and Non-Governmental Organisations (22.2\%) and a range of expertise in psychotherapy of 3 - 12 years $(M=5.40, S D=2.79)$.

Participants were recruited through advent in social media three months be- 
fore the intervention. Thirty-two participants responded positively and gave their consent to participate in the experiment. Of this total, 20 participants in the control group responded to all questionnaires.

\subsection{Materials}

\section{Empathy}

Empathy was measured by the Interpersonal Reactivity Index (IRI) scale (Davis, 1980), which has been standardised in the Greek population. It aims to study a person's general capacity for Empathy. The form contains 28 questions, categorised into four factors, two cognitive and two emotional. Specifically, these dimensions are 1) levels of perspective-taking (7 questions); 2 ) levels of fantasising (7 questions); 3) levels of emphatic concern (7 questions); 4) levels of personal distress ( 7 questions). IRI use a five-point Likert scale ranging from 0 (not describing me well) to 4 (describing me very well. Research (Bernstein \& Davis, 1982; Carey, Fox, \& Spraggins, 1988; Davis, 1980). It has a good internal consistency, ranging from 0.68 to 0.79 (Davis, 1980).

\section{Life Satisfaction}

Life satisfaction was measured by the Greek version of Diener's Satisfaction with Life Scale (Diener, Emmons, Larsen, \& Griffin, 1985), which consists of five questions. It's rated on a 7-point Likert scale $(1=$ Strongly Disagree- $7=$ Strongly Agree). The questionnaire is a short, easily corrected measure that studies how people are satisfied with their lives. The initial form of the questionnaire was developed by Neugarten, Havighurst, and Tobin (1961). The Greek translation of the questionnaire showed a correlation of 0.95 with scores on the English version for a sample of 36 bilingual Greek university women (Malikiosi-Loizos, \& Anderson, 1994). The Greek translation was also evaluated by a coefficient alpha of 0.78

\section{Self-compassion scale}

Self-compassion was measured by the Self-compassion scale developed by Neff (2003) and standardised by Karakasidou (2017) and her colleagues. SCS contains 26 items measuring six components of self-compassion. Three positive and three negative elements. It includes a 5 -item subscale of Self-Kindness, a 5-item subscale of Self-Judgment, a 4-item subscale of Common Humanity, a 4-item subscale of Isolation, a 4-item subscale of Mindfulness and a 4-item subscale of Over-Identification. Items are rated on a five-point Likert scale response scale $(1=$ almost never $-5=$ almost always $)$. It has good internal consistency the Cronbach alpha index was $\mathrm{a}=0.86$.

\section{Procedure}

The present study was conducted following the ethics from the Greek Psychological Society. A quick briefing of the experimental process was given to all participants. Any psychologists who wished to participate were asked to write down their email addresses. They were informed that their participation was voluntary and anonymous. They could withdraw from the process at any time 
and were asked to send a consent email to the researchers. In particular, they were informed that the research aims to study the efficacy of a short self-compassion program for psychologists. They were also asked to inform the researchers of their time availability. Participants who gave their participation were divided into two groups: the experimental group $(N=12)$ and control groups $(N=20)$. The division was based on the participants' ability to respond to the experiment's time requirements. The two groups received detailed instructions about the experimental conditions via email. One week before the first intervention meeting, all participants (from both groups) completed electronically via google forms-, a demographic form and three questionnaires.

The intervention included three meetings. Meetings were held once a week and lasted approximately 90 minutes. Each session focused on the theme of self-compassion. The brief form of the intervention was based on Neff's former research, which demonstrated its positive effects on overall mental health and well-being (Neff \& Germer, 2013).

\section{Program structure}

\section{Session one: An introduction to the concept of self-compassion}

Exercise 1: How would you treat a friend?

In the initial meeting, the participants learnt about the concept of self-compassion. They learnt about self-compassion's origins, its three key features, its components and its positive effects on enhancing and maintaining mental health. Furthermore, differences between self-compassion and other concepts such as self-esteem, self-pity and self-pity were explained. The members were also informed about their rights and obligations. Participants then elaborated on the first exercise, called "How would you treat a friend?". This exercise aimed to help participants understand the three components of self-compassion (self-kindness, common humanity, and Mindfulness) and encourage them to make them part of their daily lives. At the end of the exercise, the team discussed the process and their feelings during the process and agreed to write a self-compassion diary once at the end of the day for the following week. This exercise aimed to make self-kindness, common humanity, and mindfulness part of their daily life.

\section{Session two: Roleplaying}

\section{Exercise 2: The criticiser, the criticised and the compassionate observer}

At the beginning of the second meeting, the team completed a short questionnaire about the weekly exercise to provide feedback. Then, the participants were divided into three subgroups-three individuals in each group-to prepare for the activity, called "The criticiser, the criticised and the compassionate observer". The exercise aimed to help participants experientially understand the way they talk to themselves. It also encouraged them to be more compassionate towards themselves. At the end of the exercise, all the groups discussed the process, their reflection, emotions, thoughts, and possible difficulties. Then they filled out a form about the process they had experienced and agreed to continue 
writing a self-compassionate diary for the following week.

\section{Session three: Self-compassion letter}

\section{Exercise 3: Exploring self-compassion through writing}

At the beginning of the third meeting, the team completed a short questionnaire about the weekly exercise. This meeting aimed at exploring self-compassion through writing. They were encouraged to investigate an aspect of themselves that makes them feel ashamed, insecure or insufficient physical appearance, work or relationship issues and then to show unconditional acceptance, kindness, love and compassion to themselves through the letter. At the end of the exercise, the group discussed the process, reflection, emotions, thoughts, and possible difficulties. Then they evaluated the three sessions of the intervention.

\section{Post-test and follow up}

The participants completed three questionnaires one week and two months after the end of the intervention. All participants responded to the follow-up measurement. At the end of the process, an email was sent to all individuals to thank them for their participation and to inform them about the exact purpose of the experiment in which they took part.

\section{Results}

The normal distribution of the data was tested with the Shapiro-Wilk normality test $(N<200)$. The distributions were examined separately for the two groups (intervention and control group). In cases of the non-normal distribution of the data $(p<0.05)$, data was adjusted by replacing extreme values with the median value.

First, differences between self-compassion assessment before and after the intervention were examined for the intervention group. A statistically significant difference was identified for the intervention group $(t(8)=-16.562, p<0.001$, $M D=-0.89$ ), showing that the level of total self-compassion was significantly increased after the intervention $(M=3.91, S \mathrm{D}=0.45)$. On the other hand, the significant difference identified in the control group showed that self-compassion was smaller in the second assessment $(p<0.01)$. Life satisfaction was statistically significantly increased at the second assessment only for the intervention group $(t(8)=-4.069, p<0.001, M D=-2.77)$.

Differences in the components of self-compassion were also examined. For the experimental group, self-kindness was increased after the intervention (meta-assessment $M=4.00, S D=0.46)$, as well as common humanity $(M=3.77, S D$ $=0.50)$ and Mindfulness $(M=4.05, S D=0.49)$. On the other hand, self-judgement was significantly decreased $(M=2.00, S D=0.67)$ as well as Isolation $(M=1.97, S D=0.64)$ and over-identification $(M=2.38, S D=0.73)$.

Although no significant differences were identified in self-kindness, common humanity and Mindfulness, a small decrease can be seen in the means scores for the control group. The significant difference identified in self-judgement $(t(19)$ $=-2.373, p<0.05, M D=-0.08)$ resulted in an increase in self-judgement in the 
second assessment mean scores $(M=2.13, S D=0.81)$, while Isolation and over-identification mean scores were also increased in the second assessment, but this increase was not significant statistically.

Differences in Empathy were also examined between the two assessments, both for the intervention and the control groups. The results of the paired-samples t-tests showed that there was only one statistically significant difference for the component of fantasy (fantastic Empathy) only in the intervention group $(t(8)=-2.400, p<0.05, M D=-2.00)$ and means scores were higher in the assessment after the intervention $(M=23.77, S D=2.18)$ compared to the first, pre-interventional assessment $(M=21.77, S D=2.58)$. No other significant differences were identified in the intervention nor the control group. Differences between the two groups were also examined to establish whether self-compassion, life satisfaction, and Empathy were increased more in the intervention group than the control group. As far as in concerns the level of satisfaction with life, the independent samples t-test showed that there is a statistically significant difference in the assessment after the intervention $(t(24.911)=$ 2.417, $p<0.05, M D=2.87)$, with the intervention group reposting a higher mean score $(M=26.22, S D=2.33)$ compared to the control group $(M=23.35$, $S D=4.01)$.

Self-compassion was also higher in the intervention group $(M=3.91, S D=$ $0.45)$ than in the control group $(M=3.02, S D=0.58)$. This difference was also statistically significant $(t(27)=4.046, p<0.001, M D=0.89)$. Among the components of self-compassion, statistical differences were identified in all components $(p<0.05)$ except for the component of common humanity $(p>0.05)$.

Among the components of Empathy examined in this study, a statistical difference between the two groups was identified only in the level of the participants' distress $(t(27)=-2.355, p<0.05, M D=-2.61)$, with participants in the experimental group reporting a lower level of personal distress in the second assessment $(M=18.33, S D=2.64)$ compared to the participants in the control group $(M=20.95, S D=2.81)$. However, it should be noted that Personal Distress was the only variable that showed a statistically significant difference between the experimental and the control group since the pre-intervention assessment $(t(27)=-2.624, p<0.05, M D=-2.62)$ and according to the MD and mean scores, there has been no significant change in this difference. No other significant differences were identified in the components of Empathy measured with the IRI.

A follow-up assessment was also examined as part of this study. The independent samples t-test showed that the difference in participants' level of life satisfaction did not differ statistically in the follow-up $(t(25.172)=1.884, p>0.05$, $M D=-2.15$ ) between the intervention group and the control group. In particular, there was a small decrease in the mean scores of life satisfaction in the experimental group, with scores being lower in the follow-up assessment of the intervention group $(M=25.25, S D=1.90)$ compared to the assessment imme- 
diately after the intervention $(M=26.25, S D=2.49)$. Still, this inter-rating difference was not statistically significant $(t(7)=1.595, p>0.05, M D=1.00)$.

Self-compassion levels remained the same for the intervention group at the follow-up assessment $(M=3.94, S D=0.46)$ as they were in the assessment immediately after the intervention $(M=3.95, S D=41)(t(7)=0.306, p>0.05, M D$ $=0.01)$. The difference between the intervention group $(M=3.94, S D=0.46)$ and the control group $(M=3.03, S D=0.65)$ in the follow-measurement of self-compassion remained statistically significant $(t(26)=3.629, p<0.01, M D=$ $0.90)$. No significant differences were identified in empathy components, neither between the two groups nor between the meta-assessment and the follow-up assessment for none of the two groups.

\section{Discussion}

This study aimed to investigate the effect of a three-week self-compassion-focused intervention for psychologists on self-care, life satisfaction, and Empathy. The study examined whether the intervention will increase the levels of self-compassion, life satisfaction, and Empathy, comparing before and after intervention ratings and a control group. The maintenance of the effects was examined two months after the intervention.

As far as it concerns the first research hypothesis, a significant effect of the intervention was identified. Participants in the intervention group reported significantly higher self-compassion levels after the intervention. Their ratings were also significantly higher compared to their counterparts in the control group. There is limited previous research on the effectiveness of short-term self-compassion interventions. Still, the results consistently support that these interventions significantly positively affect one's self-compassion level. In a quasi-experimental study, Smeets, Neff, Alberts \& Peters (2014) found that a brief self-compassion intervention significantly increased the level of self-compassion in a sample of female students. As this study also showed, these brief self-compassion interventions impact both positive and negative self-compassion components, such as decreasing self-judgement, Isolation and over-identification, and increasing self-kindness, Mindfulness and common humanity.

Concerning life satisfaction, a significant effect of the intervention was identified. Participants in the intervention group reported significantly higher levels of life satisfaction after the intervention. Their ratings were also significantly higher compared to their counterparts in the control group. Previous studies have found that increasing self-compassion affects increasing other positive life concepts, such as life satisfaction (Gilbert, 2005; Neff et al., 2018; Yang, Zhang, \& Kou, 2016). Previous studies have also directly supported the existence of significant positive correlations between life satisfaction and self-compassion. In further support of our findings, a study conducted by Neff \& Germer (2013) reported a positive effect of a self-compassion intervention on participants' satisfaction levels with life. Smeets et al. (2014), in their study also found that the lev- 
el of life satisfaction was increased after a brief self-compassion intervention in a sample of female students, while, Mantelou \& Karakasidou (2017) in a recent study also showed that a brief 3-week self-compassion intervention could also increase positive affect levels, life satisfaction and happiness. This relationship might be explained by research findings that have provided evidence of a positive effect of self-compassion of various concepts that are positively correlated with life satisfaction, such as well-being (Neff, 2003), development of adaptive coping strategies (Neff, 2003), the rectification of maladaptive behaviours and thoughts (Neff, 2003), lower levels of negative emotions. Another explanation suggested is that self-compassion increases hope, which, as a mediating factor, leads to increases in life satisfaction levels (Yang, Zhang, \& Kou, 2016).

On the other hand, no significant differences were found in Empathy for none of the components measured with the IRI. We found no differences between the two groups after the intervention. No significant differences were found between the two assessments of the intervention group. Although there have been some research findings that suggest the existence of a relationship between Empathy and aspects of self-compassion (Birnie et al. 2010; Kingsbury, 2009; Duarte et al., 2016), there is no previous support that a self-compassion intervention can lead to increased Empathy and neither was found in our research. One possible explanation might be that it was a brief intervention. The study managed to record early effects that involve self-compassion and life satisfaction. Such an intervention might produce early results that are more focused on self-concepts rather than concepts that refer to attitudes towards and relationships with other individuals in the family, social or professional environment, as the individual tries to purposefully focus on him/herself more than he/she used to do before the intervention.

One second explanation of the lack of effect on the levels of Empathy might lie within the limitations of this study. The fact that this study's sample consists of psychotherapists might be a limitation as far as it concerns measurements of Empathy. Psychotherapists are professionally identified with the concept of Empathy, and the cognitive schema of "being empathetic" might be triggered when a therapist is asked to complete a self-reported measure of Empathy. This could explain while the ratings of Empathy remained stable between assessments. Another limitation related to the sample of psychotherapists includes the possibility that after intervention ratings might be enhanced due to personal or professional beliefs in self-compassion interventions' effectiveness. These limitations are always presented in studies that focus on psychologists and psychotherapists within psychology. As factors like self-induced prophecy, personal beliefs, increased awareness of the methods and practices of intervention might affect the results of a study. Combining self-ratings and third-person ratings (family, friends, clients etc.) might help eliminate some of these limitations and biases. Self-reported measures are also a limitation, not only for this study's sample but are generally acknowledged are susceptible to bias. Moreover, the IRI measure 
chosen for measuring Empathy is another possible limitation as it measured particular aspects of Empathy based on an interpersonal relations model.

This research was conducted at a pilot level. As the number of participants was limited, the authors cannot guarantee the representativeness of research results. Therefore, the research results should be interpreted with caution. Further research with a larger sample is necessary. Another suggestion for future research is to include more specialities in the medical services industry, such as nurses, occupational therapists, speech therapists, and other professions dealing with emotional exhaustion.

Implications of this study include contributing to providing evidence and guidelines for self-compassion interventions for psychotherapists, psychologists, and generally clinicians (doctors, nurses etc.) who suffer from compassion fatigue due to professional reasons or professionals and employees of all fields with high burnout rates. Continued contact with clients who experience personal difficulties and traumatic experiences can lead to compassion fatigue, which leads to lower effectiveness and care quality. Self-compassion interventions like the one presented in this study can help clinicians, their clients and the quality of care provided.

Further research can use this study as a basis to examine the effectiveness of brief self-compassion interventions on the levels of burnout and compassion fatigue in populations of clinicians who work with patients with severe mental or/and physical disorders (mental hospital inpatients, palliative care etc.). Moreover, self-compassion interventions' effectiveness should also be further examined as a psychological treatment component for patients' themselves.

The current study's findings may be used to design and evaluate educational interventions to improve mental health. Mental health professionals need to be able to be in touch with themselves, take care of themselves and have the right tools to protect their mental reserves. In this way, they will be on greater alert to shield their mental resilience and offer more comprehensive services to the people who need them. Good mental and physical balance is a prerequisite for a professional to take good care of their clients.

\section{Conflicts of Interest}

The authors declare no conflicts of interest regarding the publication of this paper.

\section{References}

Ackerley, G. D., Burnell, J., Holder, D. C., \& Kurdek, L. A. (1988). Burnout among Licensed Psychologists. Professional Psychology: Research and Practice, 19, 624-631. https://doi.org/10.1037/0735-7028.19.6.624

Albertson, E. R., Neff, K. D., \& Dill-Shackleford, K. E. (2015). Self-Compassion and Body Dissatisfaction in Women: A Randomised Controlled Trial of a Brief Meditation Intervention. Mindfulness, 6, 444-454. https://doi.org/10.1007/s12671-014-0277-3

Barnard, L. K., \& Curry, J. F. (2011). Self-Compassion: Conceptualizations, Correlates, \& 
Interventions. Review of General Psychology, 15, 289-303.

https://doi.org/10.1037/a0025754

Bernstein, W. M., \& Davis, M. H. (1982). Perspective-Taking, Self-Consciousness, and Accuracy in Person Perception. Basic and Applied Social Psychology, 3, 1-19. https://doi.org/10.1207/s15324834basp0301_1

Birnie, K., Speca, M., \& Carlson, L. E. (2010). Exploring Self-Compassion and Empathy in the Context of Mindfulness-Based Stress Reduction (MBSR). Stress and Health, 26, 359-371. https://doi.org/10.1002/smi.1305

Boellinghaus, I., Jones, F. W., \& Hutton, J. (2014). The Role of Mindfulness and LovingKindness Meditation in Cultivating Self-Compassion and Other-Focused Concern in Health Care Professionals. Mindfulness, 5, 129-138. https://doi.org/10.1007/s12671-012-0158-6

Burton, A., Burgess, C., Dean, S., Koutsopoulou, G. Z., \& Hugh-Jones, S. (2017). How Effective Are Mindfulness-Based Interventions for Reducing Stress among Healthcare Professionals? A Systematic Review and Meta-Analysis. Stress and Health, 33, 3-13. https://doi.org/10.1002/smi.2673

Campo, R. A., Bluth, K., Santacroce, S. J., Knapik, S., Tan, J., Gold, S. et al. (2017). A Mindful Self-Compassion Videoconference Intervention for Nationally Recruited Posttreatment Young Adult Cancer Survivors: Feasibility, Acceptability, and Psychosocial Outcomes. Supportive Care in Cancer, 25, 1759-1768. https://doi.org/10.1007/s00520-017-3586-y

Carey, J. C., Fox, E. A., \& Spraggins, E. F. (1988). Replication of Structure Findings Regarding the Interpersonal Reactivity Index. Measurement and Evaluation in Counseling and Development, 21, 102-105. https://doi.org/10.1080/07481756.1988.12022890

Davis, M. H. (1980). Interpersonal Reactivity Index. Lewiston, NY: Edwin Mellen Press. https://doi.org/10.1037/t64046-000

Diener, E. D., Emmons, R. A., Larsen, R. J., \& Griffin, S. (1985). The Satisfaction with Life Scale. Journal of Personality Assessment, 49, 71-75. https://doi.org/10.1207/s15327752jpa4901_13

Donovan, E., Rodgers, R. F., Cousineau, T. M., McGowan, K. M., Luk, S., Yates, K., \& Franko, D. L. (2016). Brief Report: Feasibility of a Mindfulness and Self-Compassion Based Mobile Intervention for Adolescents. Journal of Adolescence, 53, 217-221. https://doi.org/10.1016/j.adolescence.2016.09.009

Dorian, M., \& Killebrew, J. E. (2014). A Study of Mindfulness and Self-Care: A Path to Self-Compassion for Female Therapists in Training. Women \& Therapy, 37, 155-163. https://doi.org/10.1080/02703149.2014.850345

Duarte, J., Pinto-Gouveia, J., \& Cruz, B. (2016). Relationships between Nurses' Empathy, Self-Compassion and Dimensions of Professional Quality of Life: A Cross-Sectional Study. International Journal of Nursing Studies, 60, 1-11.

https://doi.org/10.1016/j.ijnurstu.2016.02.015

Ehret, A. M., Joormann, J., \& Berking, M. (2015). Examining Risk and Resilience Factors for Depression: The Role of Self-Criticism and Self-Compassion. Cognition and Emotion, 29, 1496-1504. https://doi.org/10.1080/02699931.2014.992394

Eriksson, T., Germundsjö, L., Åström, E., \& Rönnlund, M. (2018). Mindful Self-Compassion Training to Reduce Stress and Burnout Symptoms among practicing psychologists: A Randomized Controlled Trial of a Brief Web-Based Intervention. Frontiers in Psychology, 9, 2340. https://doi.org/10.3389/fpsyg.2018.02340

Finlay-Jones, A. L. (2014). Self-Compassion and Psychological Health among Psycholo- 
gists. Doctoral Dissertation, Perth: Curtin University.

Finlay-Jones, A. L., Rees, C. S., \& Kane, R. T. (2015). Self-Compassion, Emotion Regulation and Stress among Australian Psychologists: Testing an Emotion Regulation Model of Self-Compassion Using Structural Equation Modeling. PLoS ONE, 10, e0133481. https://doi.org/10.1371/journal.pone.0133481

Germer, C. K., \& Neff, K. D. (2013). Self-Compassion in Clinical Practice. Journal of Clinical Psychology, 69, 856-867. https://doi.org/10.1002/jclp.22021

Gilbert, P. (Ed.). (2005). Compassion: Conceptualisations, Research and Use in Psychotherapy. UK: Routledge.

Gilroy, P. J., Carroll, L., \& Murra, J. (2002). A Preliminary Survey of Counseling Psychologists' Personal Experiences with Depression and Treatment. Professional Psychology: Research and Practice, 33, 402-407. https://doi.org/10.1037/0735-7028.33.4.402

Kally, T. (2017). The Experiences of Compassion and Self-Compassion among Psychologists. Doctoral Dissertation, Bloemfontein: University of the Free State.

Karakasidou, E., Pezirkianidis, C., Galanakis, M., \& Stalikas, A. (2017). Validity, Reliability and Factorial Structure of the Self Compassion Scale in the Greek Population. Journal of Psychology \& Psychotherapy, 7, 313.

Kelly, A. C., \& Carter, J. C. (2015). Self-Compassion Training for Binge Eating Disorder: A Pilot Randomised Controlled Trial. Psychology and Psychotherapy: Theory, Research, and Practice, 88, 285-303. https://doi.org/10.1111/papt.12044

Kemper, K. J., Mo, X., \& Khayat, R. (2015). Are Mindfulness and Self-Compassion Associated with Sleep and Resilience in Health Professionals? The Journal of Alternative and Complementary Medicine, 21, 496-503. https://doi.org/10.1089/acm.2014.0281

Killian, K. D. (2008). Helping Till It Hurts? A Multimethod Study of Compassion Fatigue, Burnout, and Self-Care in Clinicians Working with Trauma Survivors. Traumatology, 14, 32-44. https://doi.org/10.1177/1534765608319083

Kingsbury, E. (2009). The Relationship between Empathy and Mindfulness: Understanding the Role of Self-Compassion. Dissertation Abstracts International: Section B: The Sciences and Engineering, 70, 3175.

Ledoux, K. (2015). Understanding Compassion Fatigue: Understanding Compassion. Journal of Advanced Nursing, 71, 2041-2050. https://doi.org/10.1111/jan.12686

Lown, B. A. (2015). Compassion Is a Necessity and an Individual and Collective Responsibility: Comment on "Why and How Is Compassion Necessary to Provide Good Quality Healthcare?”. International Journal of Health Policy and Management, 4, 613-614. https://doi.org/10.15171/ijhpm.2015.110

Malikiosi-Loizos, M., \& Anderson, L. R. (1994). Reliability of a Greek Translation of the Life Satisfaction Index. Psychological Reports, 74, 1319-1322.

https://doi.org/10.2466/pr0.1994.74.3c.1319

Mantelou, A., \& Karakasidou, E. (2017). The Effectiveness of a Brief Self-Compassion Intervention Program on Self-Compassion, Positive and Negative Affect and Life Satisfaction. Psychology, 8, 590-610. https://doi.org/10.4236/psych.2017.84038

Mosewich, A. D., Crocker, P. R., Kowalski, K. C., \& DeLongis, A. (2013). Applying Self-Compassion in Sport: An Intervention with Women Athletes. Journal of Sport and Exercise Psychology, 35, 514-524. https://doi.org/10.1123/jsep.35.5.514

Muris, P. (2016). A Protective Factor against Mental Health Problems in Youths? A Critical Note on the Assessment of Self-Compassion. Journal of Child and Family Studies, 25, 1461-1465. https://doi.org/10.1007/s10826-015-0315-3 
Neff, K. D. (2003). The Development and Validation of a Scale to Measure SelfCompassion. Self and Identity, 2, 223-250. https://doi.org/10.1080/15298860309027

Neff, K. D. (2016). The Self-Compassion Scale Is a Valid and Theoretically Coherent Measure of Self-Compassion. Mindfulness, 7, 264-274. https://doi.org/10.1007/s12671-015-0479-3

Neff, K. D., \& Germer, C. K. (2013). A Pilot Study and Randomised Controlled Trial of the Mindful Self-Compassion Program. Journal of Clinical Psychology, 69, 28-44. https://doi.org/10.1002/jclp.21923

Neff, K. D., \& Vonk, R. (2009). Self-Compassion versus Global Self-Esteem: Two Different Ways of Relating to Oneself. Journal of Personality, 77, 23-50. https://doi.org/10.1111/j.1467-6494.2008.00537.x

Neff, K. D., Long, P., Knox, M. C., Davidson, O., Kuchar, A., Costigan, A. et al. (2018). The Forest and the Trees: Examining the Association of Self-Compassion and Its Positive and Negative Components with Psychological Functioning. Self and Identity, 17, 627-645. https://doi.org/10.1080/15298868.2018.1436587

Neff, K. D., Pisitsungkagarn, K., \& Hsieh, Y.-P. (2008). Self-Compassion and Self-Construal in the United States, Thailand, and Taiwan. Journal of Cross-Cultural Psychology, 39, 267-285. https://doi.org/10.1177/0022022108314544

Neugarten, B. L., Havighurst, R. J., \& Tobin, S. S. (1961). The Measurement of Life Satisfaction. Journal of Gerontology, 16, 134-143. https://doi.org/10.1093/geronj/16.2.134

Potter, P., Deshields, T., Divanbeigi, J., Berger, J., Cipriano, D., Norris, L., \& Olsen, S. (2010). Compassion Fatigue and Burnout. Clinical Journal of Oncology Nursing, 14, E56-E62. https://doi.org/10.1188/10.CJON.E56-E62

Raab, K. (2014). Mindfulness, Self-Compassion, and Empathy among Health Care Professionals: A Review of the Literature. Journal of Health Care Chaplaincy, 20, 95-108. https://doi.org/10.1080/08854726.2014.913876

Richardson, D. A., Jaber, S., Chan, S., Jesse, M. T., Kaur, H., \& Sangha, R. (2016). SelfCompassion and Empathy: Impact on Burnout and Secondary Traumatic Stress in Medical Training. Open Journal of Epidemiology, 6, 161-166. https://doi.org/10.4236/ojepi.2016.63017

Rupert, P. A., \& Morgan, D. J. (2005). Work Setting and Burnout among Professional Psychologists. Professional Psychology: Research and Practice, 36, 544-550. https://doi.org/10.1037/0735-7028.36.5.544

Schaafsma, J. L. (2018). Compassion-Fatigue and Satisfaction: The Stress Buffering Effects of Mindfulness and Self-Compassion for Mental Health Professionals. Doctoral Dissertation, Kansas City, MO: University of Missouri-Kansas City.

Seligowski, A. V., Miron, L. R., \& Orcutt, H. K. (2015). Relations among Self-Compassion, PTSD Symptoms, and Psychological Health in a Trauma-Exposed Sample. Mindfulness, 6, 1033-1041. https://doi.org/10.1007/s12671-014-0351-x

Şenyuva, E., Kaya, H., Işik, B., \& Bodur, G. (2014). Relationship between Self-Compassion and Emotional Intelligence in Nursing Students. International Journal of Nursing Practice, 20, 588-596. https://doi.org/10.1111/ijn.12204

Shapiro, S. L., Astin, J. A., Bishop, S. R., \& Cordova, M. (2005). Mindfulness-Based Stress Reduction for Health Care Professionals: Results from a Randomised Trial. International Journal of Stress Management, 12, 164-176.

https://doi.org/10.1037/1072-5245.12.2.164

Shapiro, S. L., Brown, K. W., \& Biegel, G. M. (2007). Teaching Self-Care to Caregivers: 
Effects of Mindfulness-Based Stress Reduction on the Mental Health of Therapists in Training. Training and Education in Professional Psychology, 1, 105-115.

https://doi.org/10.1037/1931-3918.1.2.105

Smeets, E., Neff, K., Alberts, H., \& Peters, M. (2014). Meeting Suffering with Kindness: Effects of a Brief Self-Compassion Intervention for Female College Students. Journal of Clinical Psychology, 70, 794-807. https://doi.org/10.1002/jclp.22076

Yang, Y., Zhang, M., \& Kou, Y. (2016). Self-Compassion and Life Satisfaction: The Mediating Role of Hope. Personality and Individual Differences, 98, 91-95. https://doi.org/10.1016/j.paid.2016.03.086

Zessin, U., Dickhäuser, O., \& Garbade, S. (2015). The Relationship between SelfCompassion and Well-Being: A Meta-Analysis. Applied Psychology: Health and WellBeing, 7, 340-364. https://doi.org/10.1111/aphw.12051 